This is the peer reviewed version of the following article: Tucher, J., Peuntinger, K., Margraf, J. T., Clark, T., Guldi, D. M. and Streb, C. (2015), Template-Dependent Photochemical Reactivity of Molecular Metal Oxides. Chem. Eur. J., 21: 8716-8719. doi: 10.1002/chem.201501129, which has been published in final form at

http://onlinelibrary.wiley.com/doi/10.1002/chem.201501129/full This article may be used for non-commercial purposes in accordance With Wiley-VCH Terms and Conditions for selfarchiving

\title{
Template-dependent Photochemical Reactivity of Molecular Metal Oxides
}

Johannes Tucher ${ }^{[a]}$, Katrin Peuntinger ${ }^{[b]}$, Johannes T. Margraf ${ }^{[b],[c]}$, Timothy Clark $^{[c]}$, Dirk M. Guldi ${ }^{[b]{ }^{*}}$, Carsten Streb $b^{[\mathrm{a}]^{*}}$

Abstract: A combined experimental and theoretical study shows that the photooxidative activity of two isostructural metal oxide clusters depends on their internal templates. To this end, two halide-templated bismuth vanadium oxide clusters $\left[\mathrm{X}\left(\mathrm{Bi}(\mathrm{dmso})_{3}\right)_{2} \mathrm{~V}_{12} \mathrm{O}_{33}\right]^{-}\left(\mathrm{X}=\mathrm{Cl}^{-}, \mathrm{Br}^{-}\right.$ ) are reported and fully characterized. The two clusters show similar absorption features and illustrate that bismuth incorporation results in increased visible-light absorption. Significantly higher photooxidative activity is observed for the bromide-templated cluster compared with the chloride-templated one. Detailed photophysical assays and complementary density-functional theory calculations suggest that the more efficient triplet excited state formation in the $\mathrm{Br}$ containing cluster is the decisive step in the photocatalysis and is due to the heavy-atom effect of the bromide. This concept can therefore open new pathways towards the optimization of photocatalytic activity in metal oxide clusters.

Photocatalysts capable of converting sunlight into chemical reactivity hold great promise for developing sustainable energy conversion schemes. ${ }^{[1]}$ Particularly metal oxide-based photocatalysts combine high catalytic activity with stability, even under harsh reaction conditions. ${ }^{[1 e, 2]}$ Molecular metal oxides - so-called polyoxometalates (POMs) - can be used to bring together the advantages of

\footnotetext{
[a] Dr. J. Tucher, Prof. Dr. C. Streb Institute of Inorganic Chemistry, Ulm University, Albert-EinsteinAllee 11, 89081 Ulm, Germany

E-Mail: carsten.streb@uni-ulm.de; web: http://www.strebgroup.net

[b] Dr. K. Peuntinger, M.Sc. J. T. Margraf, Prof. Dr. D. M. Guldi Department of Chemistry and Pharmacy \& Interdisciplinary Center for Molecular Materials, Friedrich-Alexander-University ErlangenNuernberg, Egerlandstr. 3, 91058 Erlangen, Germany.

[c] M.Sc. J. T. Margraf, Prof. Dr. T. Clark

Department of Chemistry and Pharmacy, Computer Chemistry Center, Friedrich-Alexander-University Erlangen-Nuernberg, Nägelsbachstr. 25, 91052 Erlangen, Germany

heterogeneous metal oxides with the ability to tune photocatalytic reactivity on the molecular level.[3] POMs are anionic high-valent metaloxide clusters formed in solution by selfassembly of small oxometalate precursors. ${ }^{[3 c, 4]}$ POM assembly is often directed by anionic templates such as halides 
or oxo-anions. ${ }^{[5]}$ This modular approach has allowed the application-driven development of a wide range of functional clusters. ${ }^{[3 a, 3 b, 6]}$

Pioneered by the groups of Hill, Papaconstantinou, Yamase, and others, several tungstenbased POMs have been employed as selective photocatalysts for technologically important oxidations of alkanes, alkenes, alcohols, etc. ${ }^{[7]} \mathrm{POM}$ photocatalysts operate by a common mechanism: irradiation into a ligand-to-metal charge-transfer (LMCT) band results in the formation of oxo-centered radicals that oxidize substrates directly or via formation of hydroxyl radicals. ${ }^{[7 b, 7 d, 8]}$ However, as the LMCT bands of typical W- and Mo-based POMs lie in the UVregion, their visible-light photocatalytic activity, and, in turn, their potential for solar-energy utilization, is limited. ${ }^{[8]}$ New synthetic approaches combined with a more detailed theoretical understanding are therefore required to lay the foundations for optimized visible-light photoreactivity. ${ }^{[7 b, 9]}$

To address these challenges, we have used experimental and theoretical studies to optimize the VIS-photoactivity of POMs. Initial studies showed that structural[10] and/or chemical[9a,11] cluster modification by incorporating heterometals are promising routes: taking inspiration from well-known solid-state visible-light photocatalysts such as $\mathrm{BiVO}_{4},{ }^{[12]}$ we developed the first molecular bismuth vanadate $\left[\mathrm{H}_{3}\left(\mathrm{Bi}(\mathrm{dmsO})_{3}\right)_{4} \mathrm{~V}_{13} \mathrm{O}_{40}\right] \cdot{ }^{[11]}$ The cluster showed improved visible light absorption (up to ca. $500 \mathrm{~nm}$ ), and promising photooxidative performance. ${ }^{[11]}$

In the present study, we show that the photooxidative activity of bismuth vanadium oxide clusters is tunable by varying the central anionic template. This approach has not been investigated before, although template modification is a well-established synthetic method in vanadium oxide cluster research and a wide range of templates such as halides, oxoanions and others have been incorporated in vanadate shells. ${ }^{[5,13]}$

Here, we present the synthesis, photocatalytic activity and photophysical analysis of two isostructural bismuth vanadium oxide clusters. The compounds $(n \mathrm{Bu} 4 \mathrm{~N})\left[\mathrm{X}\left(\mathrm{Bi}(\mathrm{dmsO})_{3}\right)_{2} \mathrm{~V}_{12} \mathrm{O}_{33}\right]$ $\left(\mathrm{X}=\mathrm{Cl}^{-}(=1), \mathrm{Br}(=2)\right)$ were synthesized by reacting $\left(n \mathrm{Bu} 4 \mathrm{~N}_{3}\left[\mathrm{H}_{3} \mathrm{~V}_{10} \mathrm{O}_{28}\right]\right.$ with $\mathrm{Bi}\left(\mathrm{NO}_{3}\right)_{3} \times 5 \mathrm{H}_{2} \mathrm{O}$ and $\mathrm{NaX}$ in dimethyl sulfoxide (DMSO). The materials were obtained as single crystals (yield: $61 \%(1) ; 50 \%(2))$ by diffusion of ethyl acetate into the mother liquor. Structural analysis using single-crystal X-ray diffraction shows that the clusters are virtually isostructural, and are closely related to a cerium vanadium oxide cluster that we recently reported. ${ }^{[14]} \mathbf{1}$ and $\mathbf{2}$ are based on a halide-templated dodecavanadate cluster, $\left[\mathrm{XV}_{12} \mathrm{O}_{33}\right]^{7-}\left(\mathrm{X}=\mathrm{Cl}^{-}, \mathrm{Br}^{-}\right)$. The twelve vanadium centers are in an all-oxo square pyramidal coordination environment ([VO5]). Long- 
range electrostatic interactions between the $\mathrm{V}$ centers and the central halide template are observed.

The $\mathrm{V}$ centers are arranged in two planar hexagonal arrays that adopt a distorted hexagonal antiprismatic geometry, see Fig. 1. Both hexagonal faces of the antiprism are capped by a $\mathrm{Bi}^{\prime \prime \prime}(\mathrm{dmso})_{3}$ unit. Structural analyses reveal that the clusters are chiral and both enantiomers are observed in the crystal lattice (Fig. 1 and SI). The cluster chirality can be related to the three Z- or S-shaped tetranuclear $\left\{\mathrm{V}_{4}\right\}$ building units that make up the vanadium oxide framework of the clusters. The $\left\{\mathrm{V}_{4}\right\}$ units are chiral and $C_{2}$-symmetric, their assembly around the central halide consequently gives a chiral, $C_{2}$-symmetric cluster. ${ }^{[14]}$
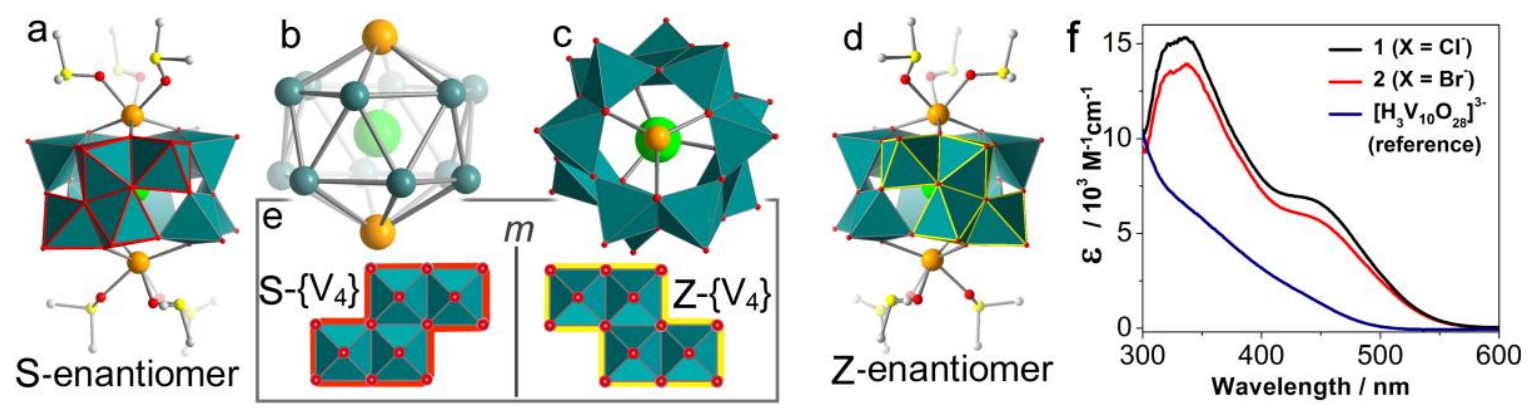

Figure 1: The isostructural cluster anions 1 and 2, $\left[\mathrm{X}\left(\mathrm{Bi}(\mathrm{dmso})_{3}\right)_{2} \mathrm{~V}_{12} \mathrm{O}_{33}\right]^{-}\left(\mathrm{X}=\mathrm{Cl}^{-}(\mathbf{1}), \mathrm{Br}^{-}(2)\right)$. (a) and (d) Representation of the Z-and S-enantiomer of the cluster, highlighting the $\left\{\mathrm{V}_{4}\right\}$ building units in red (S) and yellow (Z). (b) Metal-only framework, showing the distorted bi-capped hexagonal antiprism. (c) Top view of the cluster showing the $\mathrm{Bi}$ coordination site. DMSO-ligands omitted for clarity. (e) The chiral $\mathrm{C}_{2^{-}}$ symmetric $\left\{\mathrm{V}_{4}\right\}$ building units. (f) UV-Vis absorption spectra of $\mathbf{1}, \mathbf{2}$ and the reference cluster $\left(\left[\mathrm{H}_{3} \mathrm{~V}_{10} \mathrm{O}_{28}\right]^{3-}\right)$ in DMF, highlighting the increased visible-light absorption upon bismuth incorporation. Color scheme: vanadate units / V centers: blue; halide template: green; Bi: orange; O: red; S: yellow; C: gray; $\mathrm{H}$-atoms have been omitted for clarity.

Electrospray ionization mass-spectrometry (ESI-MS) of $\mathbf{1}$ and $\mathbf{2}$ allowed identification of the full cluster anions (with exception of the DMSO ligands) in the solution/gas phase based on $\mathrm{m} / \mathrm{z}$ and isotopic pattern calculations. For $\mathbf{1}$, the cluster anion $\left[\mathrm{ClBi}_{2} \mathrm{~V}_{12} \mathrm{O}_{33}\right]^{-}$was observed at $\mathrm{m} / \mathrm{z}$ 1592.09 (calcd. 1592.09), while the cluster anion $2\left[\mathrm{BrBi}_{2} \mathrm{~V}_{12} \mathrm{O}_{33}\right]^{-}$was observed at $\mathrm{m} / \mathrm{z}$ 1637.07 (calcd. 1637.08), see SI.

UV-Vis spectroscopy gave initial insight into the consequences of template variation: 1 and 2 show similar absorption features, which include two distinct LMCT transitions centered at 338 and $446 \mathrm{~nm}$ (Fig. 1). Higher extinction coefficients are observed for $1\left(\mathrm{X}=\mathrm{Cl}^{-}\right)$compared with 
$2(\mathrm{X}=\mathrm{Br})$. The low-energy LMCT bands tail off in the visible region up to ca. $570 \mathrm{~nm}$. Comparison with the prototype non-functionalized vanadate $\left[\mathrm{H}_{3} \mathrm{~V}_{10} \mathrm{O}_{28}\right]^{3-}$ reveals that the bismuth vanadates feature a significantly enhanced visible-light absorption.

To determine the nature of these absorption bands, we performed time-dependent densityfunctional theory (DFT) calculations using the LC-BP68 functional (see the Supporting Information for computational details and references). These calculations confirm that the excitation energies are independent of the halide templates. Natural transition orbital and electron density difference analyses confirm the LMCT character of the absorption bands, mainly involving $\mathrm{O}$ to $\mathrm{V}$ charge transfer (see $\mathrm{SI}$ ).

The photochemical reactivity of $\mathbf{1}$ and $\mathbf{2}$ was probed using photooxidation of the model dye indigo (Ind) as test reaction. All reactions were performed under de-aerated conditions to avoid oxygen-dependent autoxidation. ${ }^{[15]}$ The clusters $(1.0 \mu \mathrm{M})$ and the substrate Ind $(4.0 \mu \mathrm{M})$ were dissolved in de-aerated DMF ([Ind] : [cluster] $=4: 1$ ) and irradiated using a monochromatic $390 \mathrm{~nm}$ LED light source $\left(P_{\text {nominal }}=2 \mathrm{~W}\right)$. Indigo photooxidation was followed photospectrometrically.

Under identical conditions, faster dye photooxidation is observed for the bromide-templated cluster 2 compared with the chloride-templated cluster 1, see Fig. 2. Observed rate constants (kobs) were determined using a pseudo-first-order model. It should, however, be noted that these rates do not allow any direct implications regarding the actual reaction mechanism. The observed rates were $k_{\mathrm{obs}, 1}=44.4( \pm 0.8) \times 10^{-3} \mathrm{~min}^{-1}$ and $k_{\mathrm{obs}, 2}=66.2( \pm 3.6) \times 10^{-3} \mathrm{~min}^{-1}$. The corresponding turnover frequencies (TOF) were ca. $1.81 \mathrm{~min}^{-1}$ for 2 and ca. $1.45 \mathrm{~min}^{-1}$ for 1. Both clusters reached turnover numbers (TOM) in excess of 1600 . 

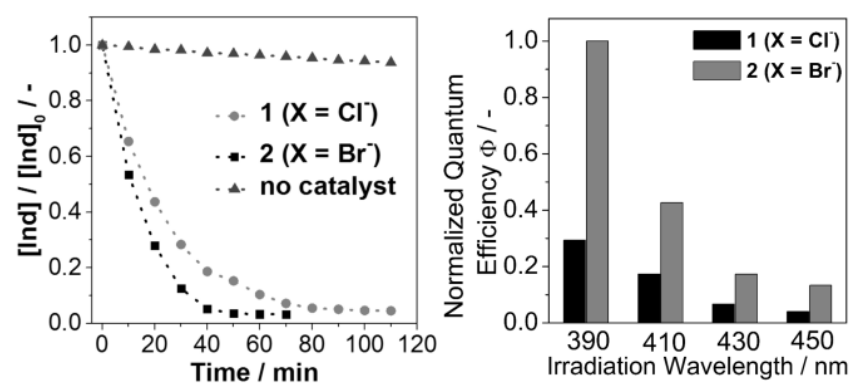

Figure 2. Left: Indigo (Ind) photooxidation by 1 and 2 under monochromatic visible light irradiation $(\lambda=$ $390 \mathrm{~nm}$ ). Conditions: solvent: DMF (de-aerated), [Ind]:[cluster] $=4: 1$; [Ind] = 4.0 $\mu \mathrm{M}$, [cluster] $=1.0 \mu \mathrm{M}$. Right: Normalized observed quantum efficiencies for the Ind photooxidation by $\mathbf{1}$ and $\mathbf{2}$ as a function of irradiation wavelength. Conditions: solvent: DMF (de-aerated), [Ind]:[cluster] $=1: 1 ;[$ Ind] $=1.0 \mu \mathrm{M}$, [cluster] $=1.0 \mu \mathrm{M}$.

Although the exact photochemical mechanism of indigo oxidation by $\mathbf{1}$ and 2 remains unknown, we opted to determine the observed quantum efficiencies pobs of $\mathbf{1}$ and $\mathbf{2}$ for the indigo photooxidation as a function of irradiation wavelength in order to gain a better understanding of the differences in cluster photoactivity. ${ }^{[16]}$ At the different irradiation wavelengths employed (390, 410, 430, and $450 \mathrm{~nm}$ ), significantly higher observed quantum efficiencies were found for 2 compared with 1 (Fig. 2), confirming that under the given reaction conditions, 2 is the more effective photocatalyst. Furthermore, decreasing quantum efficiencies for $\mathbf{1}$ and $\mathbf{2}$ were observed at longer irradiation wavelengths - this finding correlates well with the decrease in absorptivity of $\mathbf{1}$ and $\mathbf{2}$ on going from the UV to the visible part of the spectrum.

Femto- and nanosecond transient absorption measurements were performed to gain insight into the different photoactivities. Photoexcitation of $\mathbf{1}$ and 2 at $387 \mathrm{~nm}$ leads to an instantaneous bleaching of the ground-state absorption between 435 and $480 \mathrm{~nm}$, see Fig. 3 and SI. Ground-state bleaching implies the depopulation of the ground state and formation of the singlet excited LMCT state, which absorbs between 480 to $700 \mathrm{~nm}$ and gives rise to maxima at 530 and $630 \mathrm{~nm}$ (Fig. 4 and SI). Multi-wavelength analyses reveal that both the ground-state bleaching and the singlet excited state transients are short lived and decay with lifetimes of 1 to 3 ps for 1 and 2. As a consequence, a rather broad, but weak transient develops in the range between 480 and $560 \mathrm{~nm}$. A likely interpretation is an intersystem crossing (ISC) to form the corresponding triplet excited LMCT and/or inter-valence-chargetransfer (IVCT) state. 

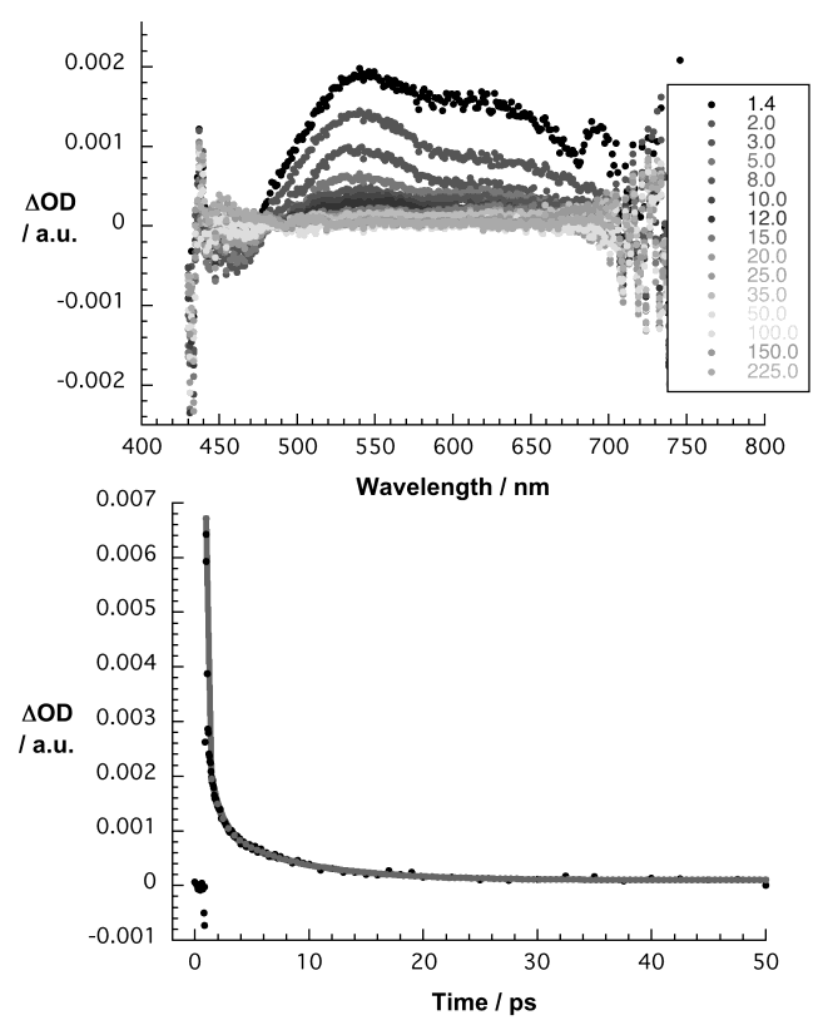

Figure 3. Top: Differential absorption spectra of 1 obtained by femtosecond flash photolysis (387 $\mathrm{nm}$, $200 \mathrm{~nJ} /$ pulse) in DMF with time delays between 0.14 and 225 ps at room temperature. Bottom: Absorption time profile of the spectra shown above at $540 \mathrm{~nm}$.

To probe the fate of the triplet excited states, complementary nanosecond transient absorption experiments were performed. These revealed a bleaching of the transient in the 480 to 560 $\mathrm{nm}$ range, which suggests decay of the triplet excited state (Fig. 4). Simultaneously, the formation of an even longer transient in the region from 560 to beyond $800 \mathrm{~nm}$ evolves. The latter is due to the formation of a radical-ion-pair state involving DMF as electron donor and 1 or 2 as electron acceptors. ${ }^{[17]}$ This type of electron-transfer is well documented, e.g. for fullerenes. ${ }^{[18]}$ In our case, the decay of the triplet excited state for $\mathbf{1}$ and $\mathbf{2}$ is strictly monoexponential with lifetimes of $20 \mathrm{~ns}$, see Fig. 4. As time progresses, the one-electron reduced species of $\mathbf{1}$ and $\mathbf{2}$ are formed, and IVCT-based absorption features are observed in the differential absorption spectra. ${ }^{[19]}$ Notably, the radical anion of 2 is stable well beyond the 1 ms range, while for 1 a lifetime of only $640 \mu$ s is observed, see SI.

To rationalize the differences in the excited state dynamics and photoreactivity of $\mathbf{1}$ and $\mathbf{2}$, we performed complementary DFT calculations. The calculated electron affinities of $\mathbf{1}$ and $\mathbf{2}$ in DMF are 4.69 and $4.68 \mathrm{eV}$, respectively. It is known for POMs that this property correlates 
with the size of the cluster cage and the total cluster charge, but is independent of the embedded anions. ${ }^{[20]}$ The vertical $\mathrm{S}_{0}-\mathrm{T}_{0}$ energy gaps were found to be 1.49 (1) and $1.53 \mathrm{eV}$ (2).

Thus, both POMs feature low-lying triplet excited states, which are known to be associated with their photocatalytic activity. ${ }^{[7 d]}$ Based on the structural and photophysical results, we suggest that the higher photocatalytic activity of $\mathbf{2}$ is based on the more efficient intersystem crossing (ISC) between the singlet and the triplet excited state for the bromide-templated species 2. ${ }^{[21]}$ This is plausible because the heavy bromide template in 2 favors spin-orbitcoupling relative to the lighter chloride template in 1 (heavy-atom effect). ${ }^{[22]}$ DFT calculations illustrate the nature of this triplet state. Its spin density is delocalized over all vanadium ions and the oxo ligands directly connected to $\mathrm{Bi}$, as well as the oxygen atoms of the DMSO ligands, see SI. Overall, the exchange of chloride with bromide has a notable impact on the efficiency of triplet excited state formation, while the electronic structure is otherwise mostly dictated by the metal oxide cage.

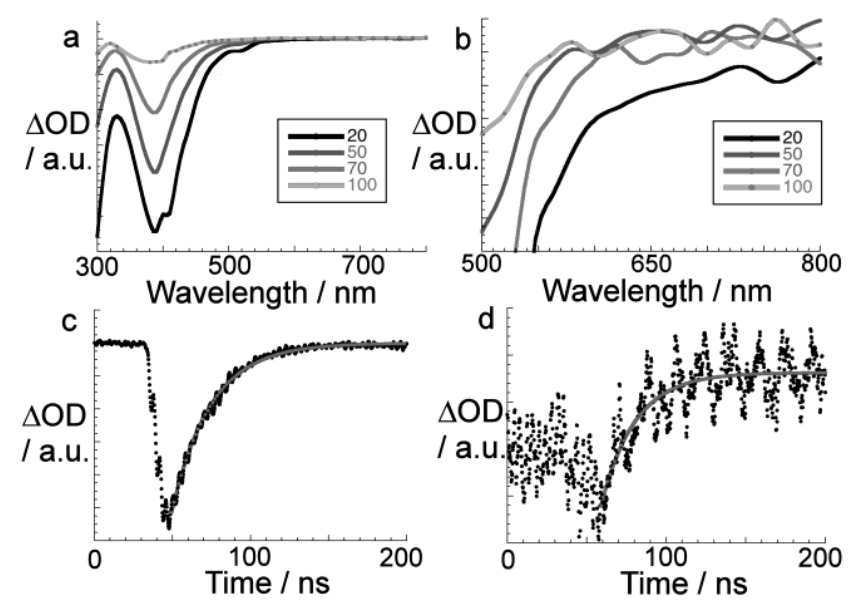

Figure 4. Top: Differential absorption spectra obtained by nanosecond flash photolysis of 1 in DMF; left: overview spectra; right: detailed view of the region between 500 to $800 \mathrm{~nm}$ (time delays 20, 50, 70, and $100 \mathrm{~ns}$ ). Bottom: Absorption time profile of the spectra shown above, plotted at $320 \mathrm{~nm}$ (left) and $600 \mathrm{~nm}$ (right).

In summary, it is shown that template exchange in isostructural bismuth vanadium oxide clusters can be used to tune their photooxidative performance. Spectroscopic and kinetic evidence and DFT calculations suggest that the catalytically active state is of triplet multiplicity. The increased photooxidative activity of the bromide-templated cluster can therefore be 
initially explained by the heavy-atom effect of the bromide, which leads to more efficient triplet excited state formation and faster dye photooxidation. Future work will be aimed at extending the cluster application to technologically important photooxidations such as visible-light driven selective alcohol oxidations and $\mathrm{C}-\mathrm{H}$-activations. Further experimental, spectroscopic and computational analyses will be performed to evaluate the general concept of templatedependent photoreactivity-tuning in POMs.

\section{Experimental Section}

Detailed experimental information is provided in the SI.

\section{Acknowledgements}

The Universities of Ulm and Erlangen-Nuernberg are acknowledged for financial support. C.S. acknowledges the Fonds der Chemischen Industrie and the DFG Graduate School GRK 1626 "Chemical Photocatalysis" (Regensburg University). J.T.M. acknowledges the BeilsteinFoundation for a scholarship. M. Dürr and Prof. Dr. I. Ivanovic-Burmazovic are acknowledged for ESI-MS measurements.

Keywords: Polyoxometalate $•$ Self-Assembly $\bullet$ Density-Functional Theory $・$ Metal Oxide $•$ Template 
[1] (a) T. P. Yoon, M. A. Ischay, J. Du, Nat. Chem. 2010, 2, 527-532; (b) A. Kudo, Pure Appl. Chem. 2007, 79, 1917-1927; (c) D. Ravelli, D. Dondi, M. Fagnoni, A. Albini, Chem. Soc. Rev. 2009, 38, 1999-2011; (d) A. L. Linsebigler, G. Q. Lu, J. T. Yates, Chem. Rev. 1995, 95, 735-758; (e) E. Borgarello, J. Kiwi, E. Pelizzetti, M. Visca, M. Grätzel, Nature 1981, 289, 158-160.

[2] (a) M. A. Fox, M. T. Dulay, Chem. Rev. 1993, 93, 341-357; (b) A. Kudo, H. Kato, I. Tsuji, Chem. Lett. 2004, 33, 1534-1539; (c) Z. Zou, J. Ye, K. Sayama, H. Arakawa, Nature 2001, 414, 625-627; (d) X. Chen, L. Liu, Y. Y. Peter, S. S. Mao, Science 2011, 331, 746-750.

[3] (a) D. L. Long, E. Burkholder, L. Cronin, Chem. Soc. Rev. 2007, 36, 105-121; (b) special POM issue: L. Cronin, A. Müller (guest eds.), Chem. Soc. Rev. 2012, 41, 7333-7334; (c) M. T. Pope, Heteropoly and isopoly oxometalates, Springer-Verlag, Heidelberg, 1983; (d) M. T. Pope, A. Müller, Angew. Chem. Int. Ed. Engl. 1991, 30, 34-48; Angew. Chem. 1991, 103, 56-70. (e) D. L. Long, R. Tsunashima, L. Cronin, Angew. Chem. Int. Ed. 2010, 49, 1736-1758; Angew. Chem. 2010, 122, 1780-1803.

[4] Special POM issue: C. Hill (guest ed.), Chem. Rev. 1998, 98, 1-300.

[5] (a) A. Müller, M. Penk, R. Rohlfing, E. Krickemeyer, J. Döring, Angew. Chem. Int. Ed. Engl. 1990, 29, 926-927; Angew. Chem. 1990, 102,927-929; (b) A. Müller, R. Rohlfing, E. Krickemeyer, H. Bögge, Angew. Chem. Int. Ed. Engl. 1993, 32, 909-912; Angew. Chem. 1993, 105, 916-918.

[6] (a) POM-themed issue: U. Kortz, T. Liu (guest eds.), Eur. J. Inorg. Chem. 2009, 2009, 5055-5276; (b) Q. S. Yin, J. M. Tan, C. Besson, Y. V. Geletii, D. G. Musaev, A. E. Kuznetsov, Z. Luo, K. I. Hardcastle, C. L. Hill, Science 2010, 328, 342-345; (c) S. G. Mitchell, C. Streb, H. N. Miras, T. Boyd, D. L. Long, L. Cronin, Nat. Chem. 2010, 2, 308-312; (d) B. Botar, Y. V. Geletii, P. Kögerler, D. A. Hillesheim, D. G. Musaev, C. L. Hill, Angew. Chem. Int. Ed. 2008, 47, 3896-3899; Angew. Chem. 2008, 120, 3960-3963.

[7] (a) C. L. Hill, C. M. Prosser-McCartha, "Photocatalytic and photoredox properties of polyoxometalate systems" in Photosensitization and Photocatalysis using inorganic and organometallic compounds (Eds.: M. Grätzel, K. Kalyanasundaram), Kluwer Academic Publishers, Dordrecht, 1993, pp. 307-326; (b) E. Papaconstantinou, Chem. Soc. Rev. 1989, 18, 1-31; (c) C. L. Hill, C. M. Prosser-McCartha, Coord. Chem. Rev. 1995, 143, 407-455; (d) T. Yamase, Catal. Surv. Asia 2003, 7, 203-217.

[8] C. Streb, Dalton Trans. 2012, 41, 1651-1659.

[9] (a) J. Tucher, Y. L. Wu, L. C. Nye, I. Ivanovic-Burmazovic, M. M. Khusniyarov, C. Streb, Dalton Trans. 2012, 41, 9938-9943; (b) P. Argitis, E. Papaconstantinou, Inorg. Chem. 1986, 25, 43864389; (c) E. Papaconstantinou, A. Hiskia, "Photochemistry and Photocatalysis of Polyoxometalates" in Polyoxometalate Molecular Science (Eds.: J. J. Borras-Almenar, E. Coronado, A. Müller, M. T. Pope), Kluwer Academic Publishers, Dordrecht, 2003, pp. 381-416; (d) A. M. Khenkin, I. Efremenko, L. Weiner, J. M. L. Martin, R. Neumann, Chem. Eur. J. 2010, 16, 1356-1364.

[10] J. Forster, B. Rösner, M. M. Khusniyarov, C. Streb, Chem. Commun. 2011, 47, 3114-3116.

[11] (a) J. Tucher, L. C. Nye, I. Ivanovic-Burmazovic, A. Notarnicola, C. Streb, Chem. Eur. J. 2012, 18, 10949-10953; (b) J. Tucher, C. Streb, Beilstein J. Nanotechnol. 2014, 5, 711-716. 
[12] (a) J. Q. Yu, A. Kudo, Adv. Funct. Mater. 2006, 16, 2163-2169; (b) A. Kudo, K. Omori, H. Kato, J. Am. Chem. Soc. 1999, 121, 11459-11467; (c) Q. X. Jia, K. Iwashina, A. Kudo, Proc. Natl. Acad. Sci. U.S.A. 2012, 109, 11564-11569.

[13] (a) W. G. Klemperer, T. A. Marquart, O. M. Yaghi, Angew. Chem. Int. Ed. Engl. 1992, 31, 49-51; (b) K. Okaya, T. Kobayashi, Y. Koyama, Y. Hayashi, K. Isobe, Eur. J. Inorg. Chem. 2009, 51565163; (c) T. Kurata, Y. Hayashi, K. Isobe, Chem. Lett. 2009, 38, 218-219; (d) N. Kawanami, T. Ozeki, A. Yagasaki, J. Am. Chem. Soc. 2000, 122, 1239-1240; (e) Y. Hayashi, Coord. Chem. Rev. 2011, 255, 2270-2280.

[14] A. Seliverstov, C. Streb, Chem. Commun. 2014, 50, 1827-1829.

[15] C. Tanielian, R. Seghrouchni, C. Schweitzer, J. Phy. Chem. A 2003, 107, 1102-1111.

[16] U. Megerle, R. Lechner, B. König, E. Riedle, Photochem. Photobiol. Sci. 2010, 9, 1400-1406.

[17] To corroborate the nature of the singly reduced species, we performed complementary spectroelectrochemical measurements. Upon reduction of $\mathbf{1}$ and $\mathbf{2}$, a decrease of the broad LMCT bands in the near UV/visible region up to $510 \mathrm{~nm}$ is observed, see Fig. 7. In fact, reducing the vanadium centers from $\mathrm{V}^{5+}$ to $\mathrm{V}^{4+}$ cancels their involvement in LMCTs, which relates to a transition from an $\mathrm{O}^{2-}$-ligand to a $\mathrm{V}^{5+}$ metal. Simultaneously, a broad, weak absorption evolves in the region from ca. 510 to beyond $800 \mathrm{~nm}$. In light of the vanadium reduction, this absorption can be assigned to intervalence charge transfer transitions. In conclusion, the same transient features are observed throughout the visible range of the spectra, irrespective of reducing the vanadium centers photochemically or electrochemically.

[18] H. Imahori, Y. Sekiguchi, Y. Kashiwagi, T. Sato, Y. Araki, O. Ito, H. Yamada, S. Fukuzumi, Chem. Eur. J. 2004, 10, 3184-3196.

[19] E. Papaconstantinou, Chem. Soc. Rev. 1989, 18, 1-31.

[20] X. Lopez, J. A. Fernandez, J. M. Poblet, Dalton Trans. 2006, 1162-1167.

[21] J. C. Koziar, D. O. Cowan, Acc. Chem. Res. 1978, 11, 334-341.

[22] S. P. McGlynn, J. Daigre, F. J. Smith, J. Chem. Phys. 1963, 39, 675-679. 
Photochemical reactivity

enhancement in two isostructural bismuth vanadium oxide clusters is observed by exchange of the central template anion. Computational and spectroscopic analyses suggest that the heavier bromide template enables a more efficient spin-orbit-coupling, leading to faster singlet-triplet transition.

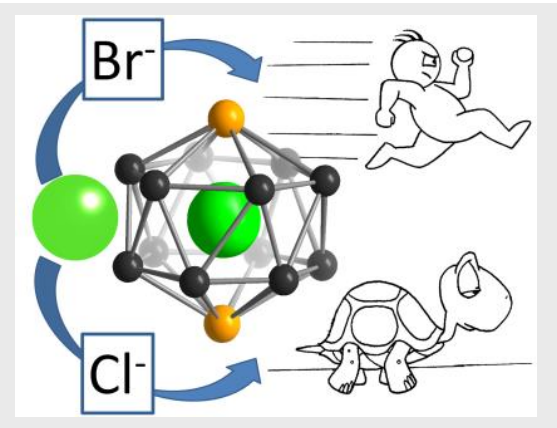

J. Tucher, K. Peuntinger, J. T. Margraf, T. Clark, D. M. Guldi*, C. Streb*

Page No. - Page No.

Template-dependent Photochemical Reactivity of Molecular Metal Oxides 